\title{
The Lagrangian stochastic model for estimating footprint and water vapor fluxes over inhomogeneous surfaces
}

\author{
Cheng-I Hsieh • Gabriel Katul
}

Received: 15 April 2008 /Revised: 9 October 2008 / Accepted: 10 October 2008 / Published online: 26 November 2008

(C) ISB 2008

\begin{abstract}
This study investigated a two-dimensional Lagrangian stochastic dispersion model for estimating water vapor fluxes and footprint over homogeneous and inhomogeneous surfaces. Over the homogeneous surface, particle trajectories were computed from a 2-D Lagrangian model forced by Eulerian velocity statistics determined by MoninObukhov similarity theory (MOST). For an inhomogeneous surface, the velocity and atmospheric stability profiles were computed using a second-order Eulerian closure model, and these local profiles were then used to drive the Lagrangian model. The model simulations were compared with water vapor flux measurements carried out above an irrigated bare soil site and an irrigated potato site. The inhomogeneity involved a step change in surface roughness, humidity, and temperature. Good agreement between eddy-correlationmeasured and Lagrangian-model-predicted water vapor fluxes was found for both sites. Hence, this analysis demonstrates the practical utility of second-order closure models in conjunction with Lagrangian analysis to estimate the scalar footprint in planar inhomogeneous flows.
\end{abstract}

Keywords Eulerian-Lagrangian hybrid approach . Flux variation along a transition $\cdot$ Footprint

\section{C.-I. Hsieh $(\bowtie)$}

Department of Bioenvironmental Systems Engineering,

National Taiwan University,

Taipei 10617, Taiwan

e-mail: hsieh@ntu.edu.tw

G. Katul

Nicholas School of the Environment and Earth Sciences,

Duke University,

Durham, NC 27708-0328, USA

\section{Introduction}

Developing explicit relationships between scalar sources and sinks at the surface and turbulent fluxes in the atmosphere is becoming a central research topic in biosphere-atmosphere exchange given the proliferation of the number of sites participating in FluxNet, a global network aimed at quantifying long-term carbon dioxide $\left(\mathrm{CO}_{2}\right)$ and water vapor $\left(\mathrm{H}_{2} \mathrm{O}\right)$ fluxes using the eddycovariance method (e.g., Baldocchi et al. 2001). In deriving a prognostic relationship between the flux and source areas (or footprint), both analytical (Eulerian) (e.g., Horst and Weil 1994; 1992; Gash 1986) and Lagrangian (e.g., Kljun et al. 2002, 2004; Flesch 1996; Flesch et al. 1995; Leclerc and Thurtell 1990) models have been employed. Large eddy simulations (LES) of footprint have also been investigated with some success, albeit for a restricted domain (e.g., Leclerc et al. 1997). About a decade ago, Finn et al. (1996) concluded that analytical and Lagrangian models provide similar estimates of footprint distances in homogeneous flows. However, they indicated that the Lagrangian model has a broader range of applications (e.g., for variable source strength cases) when compared to the analytical model, thus permitting a wider range of field conditions to be incorporated (e.g., Kaharabata et al. 1997; Schmid 2002; Marcolla and Cescatti 2005), which is desirable for a large number of FluxNet sites.

One difficulty in implementing the Lagrangian model for estimating flux and footprint derives from the need to specify the velocity field and atmospheric stability effects, especially when the flow is not planar homogeneous (Schmid 2002). For a stationary and planar homogeneous flow field, these velocity profiles can be readily estimated from Monin-Obukhov similarity theory (MOST). For canopy flows, or above a non-homogeneous surface such 
as a general irrigated agricultural area where a step change in surface roughness, moisture, and temperature conditions exists, MOST is no longer applicable. Hence, the Lagrangian model in conjunction with MOST cannot be readily applied.

Above non-homogeneous surfaces, flow fields can be generated by measurements or numerical simulations. Naslund et al. (1994) and Lee and Naslund (1998) adopted a Lagrangian model to simulate turbulent dispersion around buildings where the flow field was parameterized by the standard $\mathrm{k}-\varepsilon$ closure model. With a second-order closure model for calculating the flow field, Bouvet et al. (2007, 2006) applied a Lagrangian stochastic model to study heavy particle transport in windbreak flows. Their results showed that this hybrid approach could reasonably reproduce the measurements. Luhar and Rao (1994) used a second-order closure model (Rao et al. 1974) to first solve the velocity and temperature fields above a step change in surface conditions, and these flow fields were then used to drive the Lagrangian model and estimate the flux and footprint.

The above mentioned "Lagrangian dispersion-Eulerian closure" hybrid approach is attractive for scalar flux and footprint predictions since this method avoids the assumption of planar homogeneous flow conditions. Despite this progress, two important issues requiring systematic investigation remain: (1) the Lagrangian model calculations of Luhar and Rao (1994) remain one-dimensional and do not consider the fluctuation component of the streamwise velocity, and (2) this linkage between Lagrangian and higher-order Eulerian closure models still awaits systematic field testing across a range of inhomogeneity types.

In this study, a two-dimensional Lagrangian model is investigated to explore the scalar flux and footprint over homogeneous and inhomogeneous surfaces where the fluctuation part of the streamwise velocity is explicitly considered. Field-testing of the Lagrangian model above two homogeneous and two inhomogeneous surfaces was undertaken. The homogeneous tests were carried out over a sagebrush canopy and a peach orchard site, respectively, where SF6 tracer fluxes were measured. The first inhomogeneous test was an irrigated bare soil site where the source area for water vapor is well defined within a larger nonirrigated bare soil region (i.e., no change in momentum roughness). The second inhomogeneous test was an irrigated potato field surrounded by a desert. Since the airflow from dry to wet cannot be treated as homogeneous, the Lagrangian model must be linked to a two-dimensional second-order closure model to estimate water vapor flux and footprint. Discussions on the performance of the Lagrangian model along with comparisons with these field experiments are presented.

\section{Methods}

The Lagrangian stochastic dispersion model

The Lagrangian stochastic model is based on the assumption that the evolution of particle position and velocity is a Markov process. The basic concepts, details, and many references can be found in Rodean's (1996) monograph. Following this assumption, the stochastic equations describing particle velocity and position are

$d u_{i}=a_{i}\left(x_{i}, u_{i}, t\right) d t+b_{i j}\left(x_{i}, u_{i}, t\right) d \lambda_{j}$ $u_{i}(t)=u_{i}\left(t_{0}\right)+\int_{t_{0}}^{t} d u_{i}$

and

$d x_{i}=u_{i} d t \quad x_{i}(t)=x_{i}\left(t_{0}\right)+\int_{t_{0}}^{t} d x_{i}$

where the sub-indexes $i$ and $j=1,2$, or 3 with summation implied over repeated indexes, $x_{1}=x, x_{2}=y, x_{3}=z$, and $u_{1}=$ $u, u_{2}=\mathrm{v}, u_{3}=w$ are the longitudinal, lateral, and vertical velocities, respectively (since two-dimensional cases are considered, $i$ and $j$ each take on values of 1 and 3 ), and $t_{0}$ is the initial time. As is common in stochastic differential equations, $a$ can be interpreted as a drift coefficient, $b$ is the random acceleration coefficient, $\mathrm{d} t$ is the time interval, and $\mathrm{d} \lambda$ is a Gaussian random increment with zero mean and variance $\mathrm{d} t$. Once coefficients $a$ and $b$ are determined from the flow field, then the formulation for particle trajectories can be established.

For determining $a$, Thomson's (1987) well-mixed condition is used, while $b$ can be determined from Kolmogorov's Lagrangian theory for the inertial subrange. The well-mixed condition states that if the tracer particles are initially uniformly distributed (well-mixed) in velocity and position space, they should remain so at all times during the dispersion process. Unfortunately, the well-mixed condition is not sufficient for selecting a unique solution for the coefficient $a$ when the flow is two- or three-dimensional. Efforts have been made to provide a criterion for distinguishing better Lagrangian stochastic formulations within the "well-mixed" family (e.g., Reynolds 1998a, b; Borgas et al. 1997; Wilson and Flesch 1997), but improvements over Thomson's (1987) model have been rather variable (Sawford 1999; Kurbanmuradov and Sabelfeld 2000). For this reason, the steady state solution of Thomson's model is adopted, with coefficients $a$ and $b$ given by

$a_{i}=-b_{i k} b_{j k}\left(V^{-1}\right)_{j k}\left(u_{k}-U_{k}\right)+\frac{\phi_{i}}{g_{a}}$ 


$$
\begin{aligned}
\frac{\phi_{i}}{g_{a}}= & \frac{1}{2} \frac{\partial V_{i l}}{\partial x_{l}}+\frac{\partial U_{i}}{\partial t}+U_{l} \frac{\partial U_{i}}{\partial x_{l}} \\
+ & \left(\frac{1}{2}\left(V^{-1}\right)_{l j}\left(\frac{\partial V_{i l}}{\partial t}+U_{m} \frac{\partial V_{i l}}{\partial x_{m}}\right)+\frac{\partial U_{i}}{\partial x_{j}}\right) \\
& \left(u_{j}-U_{j}\right)+\frac{1}{2}\left(V^{-1}\right)_{l j} \frac{\partial V_{i l}}{\partial x_{k}}\left(u_{j}-U_{j}\right)\left(u_{k}-U_{k}\right)
\end{aligned}
$$

$b_{i j}=\delta_{i j}\left(C_{0} \varepsilon\right)^{1 / 2} \approx \delta_{i j}\left(\frac{2 \sigma_{w}^{2}}{t_{L}}\right)^{1 / 2}$.

In Eqs. 3a, 3b, and 4, the sub-indices $i$ and $j=1,2$, and 3 , with summation over the repeated index, $U_{i}$ is the mean Eulerian velocity $\left(U_{1}=\mathrm{U}\right.$, mean streamwise velocity, $U_{2}=V$, mean lateral velocity, and $U_{3}=W$, mean vertical velocity), the tensor $V_{i j}$ is defined as $V_{i j}=\overline{\left(u_{i}-U_{i}\right)\left(u_{j}-U_{j}\right)}$, the over bar denotes ensemble average, $\sigma_{\mathrm{w}}{ }^{2}$, vertical velocity variance is the one-dimensional form of $V_{i j}, \mathrm{C}_{0}$ is Lagrangian Kolmogorov constant $(\approx 3.0)$ and $\varepsilon$ is the mean turbulence kinetic energy dissipation rate; the quantity $\mathrm{C}_{0} \varepsilon$ is approximated by $2 \sigma_{\mathrm{w}}{ }^{2} / t_{\mathrm{L}}$, where $t_{\mathrm{L}}$ is the Lagrangian decorrelation time scale.

In Eqs. 3a and 4, non-Gaussian turbulence is not considered. It was noticed that models that include nonGaussian turbulence do not outperform those with a Gaussian turbulence assumption (Wilson and Sawford 1996). The derivation of Eqs. 3a-4 can be found in Thomson (1987) and will not be repeated here. Using Eqs. 1-4, trajectories of fluid particles can be computed and concomitant scalar fluxes and footprint can be obtained.

The velocity field

\section{Monin-Obukhov similarity theory}

To drive the Lagrangian model, the first and second moments of the velocity field have to be determined a priori. For a stationary and planar homogeneous flow, these profiles can be expressed via MOST as

$W(z)=0$

$U(z)=\frac{u_{*}}{k}\left[\ln \left(\frac{z-d}{z_{o}}\right)-\psi_{m}\right]$

$\sigma_{w}=1.25 u_{*}\left(1-3 \frac{z-d}{L}\right)^{1 / 3}$ for $z / L<0 ;$ where $u_{*}$ is the friction velocity, $z_{\mathrm{o}}$ is the surface roughness, $d$ is the zero plane displacement, $L$ is the Obukhov length, $k$ $(=0.4)$ is von Karman constant, and $\psi_{\mathrm{m}}$ is the momentum stability correction function (Brutsaert 1984). The difficulty of driving a two-dimensional Lagrangian model stems from the specification of $\sigma_{\mathrm{u}}$ (the standard deviation of $U$ ) profile since $\sigma_{\mathrm{u}}$ may not follow MOST scaling. Here, two profiles of $\sigma_{\mathrm{u}}$ are considered:

$$
\begin{gathered}
\sigma_{u}=2.5 u_{*}\left(1-3 \frac{z-d}{L}\right)^{1 / 3} \text { for } z / L<0 \\
\sigma_{u}=2.5 u_{*} \text { for } z / L \geq 0
\end{gathered}
$$

$$
\begin{aligned}
& \sigma_{u}=\left(0.35 w_{*}^{2}+2.0 u_{*}^{2}\right)^{1 / 2}, w_{*}=\left(-\frac{u_{*}^{3} h_{b}}{L k}\right)^{1 / 3} \text { for } z / L<0 \\
& \sigma_{u}=2.5 u_{*} \text { for } z / L \geq 0
\end{aligned}
$$

In Eq. 8, $\sigma_{\mathrm{u}}$ is described as a function of $(z-d) / L$ as suggested by Kader and Yaglom (1990) and Hsieh and Katul (1997). In Eq. 9, $\sigma_{\mathrm{u}}$ does not obey MOST for unstable conditions $(z / L<0)$ and is a function of a convective velocity scale $w_{*}$ and the boundary layer height, $h_{\mathrm{b}}(=2,000 \mathrm{~m}$, assumed in this study). The stability correction functions $\left(\psi_{m}\right)$ for stable and unstable conditions and $t_{\mathrm{L}}$ profiles are described in Appendix A. The input parameters for this two-dimensional Lagrangian model are: $u_{*}, h_{\mathrm{b}}, z_{\mathrm{o}}, d, L$, and measurement height, $z_{\mathrm{m}}$, where $z_{\mathrm{o}}$ and $d$ can be approximated by $0.1 \mathrm{~h}$ and $0.66 \mathrm{~h}$ (Campbell and Norman 1998), respectively, and $h$ is the canopy height.

\section{Second-order closure model}

For an inhomogeneous surface, where a step change in momentum and scalars occurs, the velocity and atmospheric stability fields cannot be computed from MOST as the flow is no longer planar-homogeneous. Here, a second-order closure model is proposed instead of MOST. This model consists of ten equations to solve the first and second moments of the velocity, temperature, and atmospheric stability fields. In the following equations, $U, W$, and $\Theta$ are the mean streamwise velocity, mean vertical velocity and mean temperature, respectively; $u^{\prime}, v^{\prime}$, and $w^{\prime}$ are the fluctuations of streamwise, lateral, and vertical velocities, respectively; $\theta$ is the fluctuation of temperature, and Einstein's summation is applied, i.e., repeated indices in one term represent summation.

1) Three mean field equations (the conversation equations of momentum, mass, and temperature) for streamwise velocity $(U)$, vertical velocity $(W)$, and temperature $(\Theta)$.

$\sigma_{w}=1.25 u_{*}$ for $z / L \geq 0$ 


$$
\begin{gathered}
U \frac{\partial U}{\partial x}+W \frac{\partial U}{\partial z}=-\frac{\partial \overline{u^{\prime} w^{\prime}}}{\partial z} \\
\frac{\partial U}{\partial x}+\frac{\partial W}{\partial z}=0 \\
U \frac{\partial \Theta}{\partial x}+W \frac{\partial \Theta}{\partial z}=-\frac{\partial \overline{\theta w^{\prime}}}{\partial z}
\end{gathered}
$$

In Eq. 10a, the pressure gradient $\partial \bar{p} / \partial x$ and velocity variance $\partial \overline{u^{\prime 2}} / \partial x$ terms are neglected as suggested by Peterson (1972).

2) Four Reynolds stress $\left(\overline{u^{\prime} u^{\prime}}, \overline{v^{\prime} v^{\prime}}, \overline{w^{\prime} w^{\prime}}, \overline{u^{\prime} w^{\prime}}\right)$ budget equations for velocity variance and covariance.

$$
\begin{aligned}
U_{j} \overline{\left(\overline{u_{i}^{\prime} u_{k}^{\prime}}\right), j}+\left(\overline{u_{j}^{\prime} u_{k}^{\prime}}\right) U_{i, j}+\left(\overline{u_{j}^{\prime} u_{i}^{\prime}}\right) U_{k, j}-\frac{g}{T_{o}}\left(\overline{u_{k}^{\prime} \theta} \delta_{3 i}+\overline{u_{i}^{\prime} \theta} \delta_{3 k}\right) \\
=-\left(\overline{u_{i}^{\prime} u_{k}^{\prime} u_{j}^{\prime}}\right){ }_{, j}-\left(\overline{u_{k}^{\prime} p_{, i}}+\overline{u_{i}^{\prime} p_{, k}}\right)-2 \bar{\varepsilon} \frac{\delta_{i k}}{3}
\end{aligned}
$$

where the differentiation is denoted by a comma, the sub-indices $i=k=1,2$, or 3 , or $i=1$ and $k=3\left(u_{1}^{\prime}=\right.$ $\left.u^{\prime}, u_{2}{ }^{\prime}=v^{\prime}, u_{3}{ }^{\prime}=w^{\prime}\right), \delta$ is the Kronecker delta tensor, $p$ is the fluctuating kinematic pressure, $T_{\mathrm{o}}$ is the constant representative mean temperature, and $\bar{\varepsilon}$ is the mean dissipation rate of turbulence kinetic energy $\left(=\overline{u_{i}^{\prime} u_{i}^{\prime}} / 2\right)$.

3) Two budget equations for heat fluxes $\left(\overline{\theta u^{\prime}}\right.$ and $\left.\overline{\theta w^{\prime}}\right)$.

$$
\begin{aligned}
& U_{j}\left(\overline{\theta u_{i}^{\prime}}\right),{ }_{j}+\left(\overline{\theta u_{j}^{\prime}}\right) U_{i, j}+\left(\overline{u_{j}^{\prime} u_{i}^{\prime}}\right) \Theta_{, j}-\frac{g}{T_{o}}\left(\overline{\theta \theta} \delta_{3 i}\right) \\
& \quad=-\left(\overline{\theta u_{i}^{\prime} u_{j}^{\prime}}\right){ }_{, j}-(\overline{\theta p, i})
\end{aligned}
$$

where $i=1$ or 3 .

4) One equation for turbulence kinetic energy dissipation rate $(\bar{\varepsilon})$. Based on mixing length theory, $\bar{\varepsilon}$ was calculated as

$$
\bar{\varepsilon}=k_{\varepsilon}\left(\overline{u_{i}^{\prime} u_{i}^{\prime}}\right)^{3 / 2} / k_{L}
$$

where $k_{\varepsilon}$ is a similarity constant and $k_{\mathrm{L}}$ is a mixing length scale (Shir 1972).

A review of several closure techniques can be found in Stull (1988) and is not repeated here. The closure formulations based on Wichmann and Schaller (1986) are adopted in this study. The above governing equations were numerically integrated by a Dufort-Frankel explicit finite difference scheme. The initial profiles for the upstream surface were obtained by substituting the upstream boundary conditions in the governing equations and numerically integrating the latter in $\mathrm{x}$, without any change in boundary condition, until steady-state equilibrium distributions were established. The methods for assigning boundary conditions are described in Appendix B.

Flux and footprint calculations

To calculate fluxes and footprints, scalar particles are released from the canopy height and reflected at $d+z_{\mathrm{o}}$. For a stationary horizontally homogeneous surface, calculations of flux and footprint depend only on the relative distance between the flux measurement point and the emission point; the scalar flux, $F$, at the point $(x, z)$ can be calculated using (Hsieh et al. 2000)

$F(x, z)=S\left(\frac{n_{\uparrow}-n_{\downarrow}}{N}\right)$,

where $S$ is the surface source strength $\left(\mathrm{kg} \mathrm{m}^{-2} \mathrm{~s}^{-2}\right), n_{\uparrow}$ and $n_{\downarrow}$ are the number of particles reaching height $z$ at position $x$ with upward and downward vertical velocities, respectively, and $N$ is the total number of particles released. The footprint, $f(x, z)$, can be calculated by differentiating the normalized flux [i.e., $F(x, z) / S$ ] with respect to $x$ at $(x, z)$ as

$f(x, z)=\frac{\partial F(x, z) / S}{\partial x}$

In essence, the footprint describes the relative contribution of each source element to the measured flux.

However, for an inhomogeneous surface, the flux and footprint calculations will also depend on the actual location of the emission point. In this case, flux estimation necessitates placement of a large number of upwind emission points along a line source from the sensor location and computation of the following:

$$
C(x, z)=\int_{-\infty}^{x} \int_{t 0}^{t} S\left(x_{0}\right) P\left(x, z, t \mid x_{0}, z_{0}, t_{0}\right) d t_{0} d x_{0}
$$

$$
\begin{aligned}
F(x, z) & =\overline{w c} \\
& =\int_{-\infty}^{x} \int_{t 0}^{t} w S\left(x_{0}\right) P\left(x, z, t \mid x_{0}, z_{0}, t_{0}\right) d t_{0} d x_{0}
\end{aligned}
$$

where $C$ and $c$ are the mean and instantaneous scalar concentrations, respectively, $w$ is the Lagrangian vertical velocity at $(x, z)$, and $P$ is the transition probability density function $\left(\mathrm{m}^{-2}\right)$ that describes the probability density of a tracer particle originally released at $\left(x_{0}, z_{0}, t_{0}\right)$ to be found at $(x, z, t)$. Suppose the line source is divided into $n$ segments, each having a steady and uniform source density $S_{\mathrm{j}}$ over its width, $\Delta x_{\mathrm{j}}$, where $j=1, \ldots, n$. Equation 17 can then be simplified and the flux at the measurement point $\left(x_{\mathrm{m}}, z_{\mathrm{m}}\right)$ can be calculated as

$$
\begin{aligned}
F\left(x_{m}, z_{m}\right) & =\sum_{j=1}^{n} \Delta x_{j} S_{j}\left(x_{j}\right) \frac{M_{j}^{\uparrow}\left(x_{m}+\Delta x, z_{m}\right)}{\Delta x} \\
& -\Delta x_{j} S_{j}\left(x_{j}\right) \frac{M_{j}^{\downarrow}\left(x_{m}+\Delta x, z_{m}\right)}{\Delta x}
\end{aligned}
$$


where $M_{j}^{\uparrow}\left(x_{m}+\Delta x, z_{m}\right)$ and $M_{j}^{\downarrow}\left(x_{m}+\Delta x, z_{m}\right)$ are the probabilities of particles from source $S_{\mathrm{j}}$ passing the sampling location between $\left(x_{\mathrm{m}}, z_{\mathrm{m}}\right)$ and $\left(x_{\mathrm{m}}+\Delta x, z_{\mathrm{m}}\right)$ with positive and negative vertical velocities, respectively; here, $\Delta x$ is the width of the sampling point. And the source strength, $S$ $(x)$, over an inhomogeneous surface, where a step change in surface conditions occurs at $x=0$, can be specified by

$S(x)=\left\{\begin{array}{lll}S_{1} & \text { for } & x<0 \\ S_{2} & \text { for } & x \geq 0\end{array}\right\}$,

as suggested by McAneney et al. (1994) and Brunet et al. (1994).

\section{Experiments}

Four experimental data sets were used to test the Lagrangian model. For homogeneous conditions, SF6 flux data collected above (1) a sagebrush canopy $\left(z_{\mathrm{o}}=0.14 \mathrm{~m}, h=\right.$ $0.75 \mathrm{~m}$; Leclerc et al. 1997) and (2) a peach orchard canopy $\left(z_{\mathrm{o}} \approx 0.4\right.$ to $0.54 \mathrm{~m}, h \approx 3.1$ to $4.2 \mathrm{~m}, d \approx 2.1$ to $2.8 \mathrm{~m}$; Leclerc et al. 2003) were employed. For inhomogeneous conditions, the first experiment was carried out above an irrigated bare soil site, where the Lagrangian model was tested against the measured water vapor flux (LE) at a fixed point. The second experiment was performed above an irrigated potato site, where the Lagrangian model was tested against water vapor flux measurements conducted along a progression of distances downwind from a transition.

\section{Sagebrush experiment}

This field experiment was conducted over a sagebrush canopy near Richland (WA), during June 1992 (Leclerc et al. 1997). This site is located in a flat, $40 \mathrm{~km}$ basin. The canopy height and surface roughness were 0.75 and $0.14 \mathrm{~m}$, respectively.

A $400 \mathrm{~m}$ long line source of SF6 tracer was deployed at the canopy top along the SW-NE directions. The SF6 tracer was continuously released at a steady rate from the line source while the wind was from the northwest. Four eddycovariance (EC) systems located downwind at 50, 100, 175, and $250 \mathrm{~m}$ along a line normal to the line source were used to measure SF6 fluxes. Each EC system was set at $10 \mathrm{~m}$ above the ground and consisted of a three-dimensional sonic anemometer and a fast-response tracer analyzer. Both raw and $5 \mathrm{~min}$ averages of all variables were stored on a continuous basis. Three-dimensional coordinate rotation was made to set the mean lateral and vertical velocities to zero. SF6 fluxes were then calculated for each half-hour period. The experimental setup is shown in Fig. 1a.

Two periods of data on Julian days 168 and 172 were used in the model validation. The mean $u *$ was about $0.4 \mathrm{~m} / \mathrm{s}$ at GMT $1740-2232$ hours on day 168 , and $0.29 \mathrm{~m} / \mathrm{s}$ at GMT
1412-1507 hours on day 172. More details of this experiment can be found in Leclerc et al. (1997).

\section{Peach orchard experiment}

This experiment was carried out over a peach orchard field, approximate $200 \mathrm{~m} \times 250 \mathrm{~m}$, at Hollonville (GA) during July-September 1998 (Leclerc et al. 2003). At the onset of this experiment, the canopy height was $3.1 \mathrm{~m}$. Later in the summer, the canopy had grown taller and the canopy height was $4.2 \mathrm{~m}$. The surface roughness and zero-plan displacement were $0.4-0.55$ and $2.1-2.8 \mathrm{~m}$, respectively.

Two, $100 \mathrm{~m}$ long, line sources of SF6 tracer were deployed at the canopy top for a broad range of wind directions. Four towers equipped with a three-dimensional sonic anemometer and a fast response SF6 analyzer at $6 \mathrm{~m}$ above the ground were used to measure the tracer fluxes. The SF6 tracer was continuously released at a steady rate from one single line source. Depending on the wind direction, these flux towers were at $8,30,55$, and $65 \mathrm{~m}$ downwind from the northern line source, and at 9, 19, 42, and $55 \mathrm{~m}$ downwind from the southern line source (Fig. 1b).

A CR-10X datalogger was used to collect the $8 \mathrm{~Hz}$ timeseries data. Three-dimensional coordinate rotation was made to set the mean lateral and vertical velocities to zero. SF6 fluxes were then calculated for each half-hour period. Data were discarded when the wind was not from the preferred direction. Data collected on 16 July, 22 September, and 23 September 1998 were used for this study. Readers are referred to Leclerc et al. (2003) for more experimental details.

\section{Bare soil site}

This experiment was performed above a uniformly irrigated bare soil patch within a large dry soil field at the Campbell tract facility at the University of California in Davis (CA). The Campbell tract facility is a $500 \mathrm{~m} \times 500 \mathrm{~m}$ bare soil site $\left(z_{\mathrm{o}}=1.7 \mathrm{~mm}\right.$, determined from the mean wind profile as described in Hsieh et al. 1997). The site is equipped with a sprinkler irrigation system capable of irrigating a $120 \mathrm{~m} \times$ $110 \mathrm{~m}$ soil patch with uniformity coefficients of about $85 \%$ (see Katul and Parlange 1992; Parlange et al. 1992 for details on the irrigation system). The irrigation was carried out on the evening of August 21 1993, and only data collected after irrigation were used. The edge of the irrigated boundary from the measurement tower varied from $80 \mathrm{~m}$ to $100 \mathrm{~m}$ depending on the wind direction. Two EC systems, each consisting of a CA27 one-dimensional sonic anemometer and a Krypton hygrometer, were used to measure the vertical velocity and LE at $1.12 \mathrm{~m}$ and $2.9 \mathrm{~m}$ above the ground surface. To calculate the absolute 
Fig. 1 a Experimental set up over the sagebrush site. Four eddy-covariance(EC) systems were used to measure SF6 fluxes from the line source at different horizontal positions. b Experimental set up over the peach orchard site. Two SF6 line sources for releasing SF6 were deployed at the canopy top depending on wind direction. $\mathbf{c}$ Experimental set up over the bare soil site. Two EC systems were used to measure water vapor fluxes at 1.12 and $2.9 \mathrm{~m}$. The fetch was about $100 \mathrm{~m}$. d Experimental set up over the potato site. A stationary EC system was set at $800 \mathrm{~m}$ from the transition edge to measure water vapor flux. The solid dots $(\bullet)$ on the potato field denote the locations of the mobile EC systems. The radius of each irrigation circle was $400 \mathrm{~m}$ a
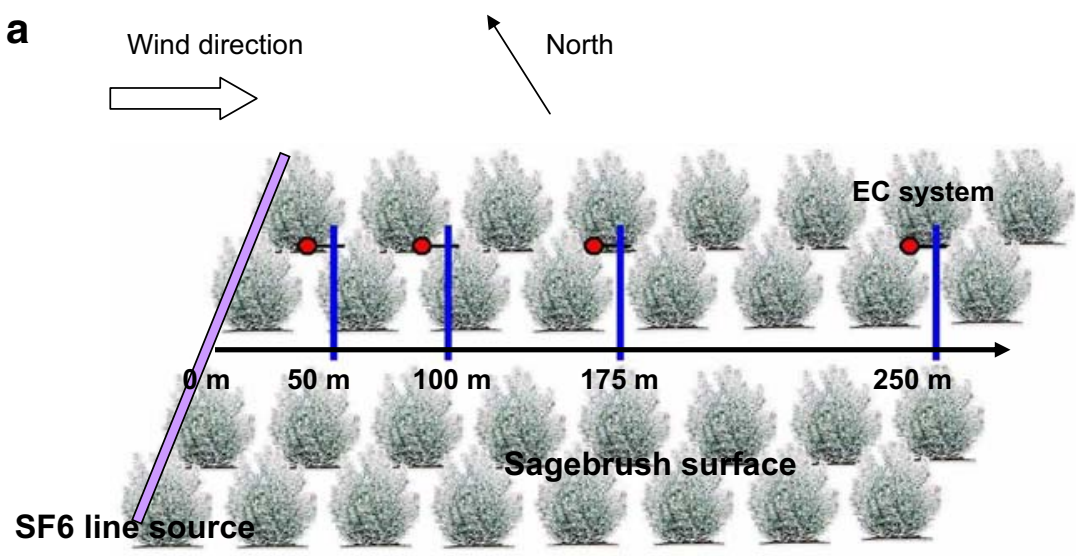

b

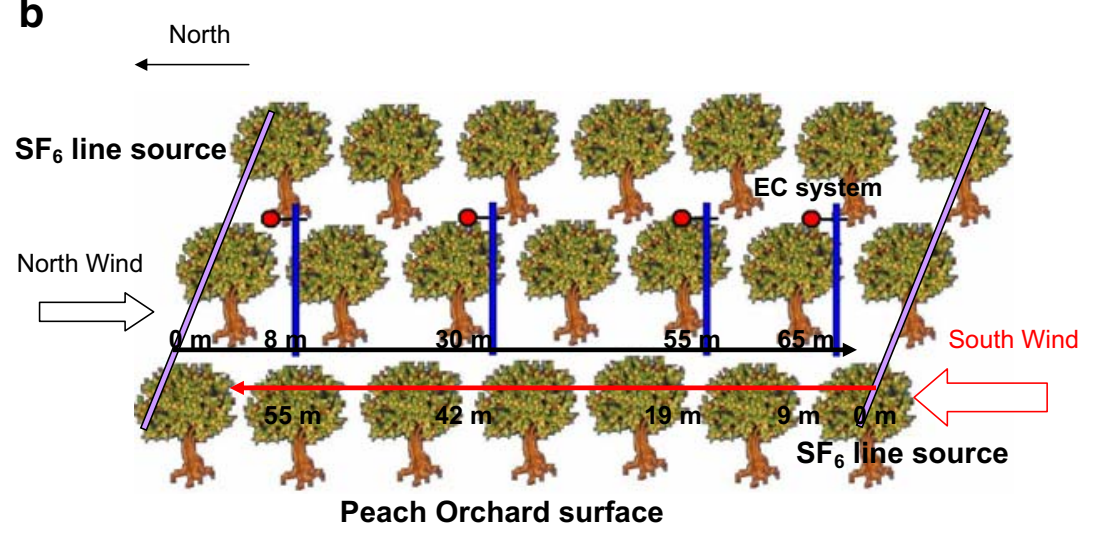

C

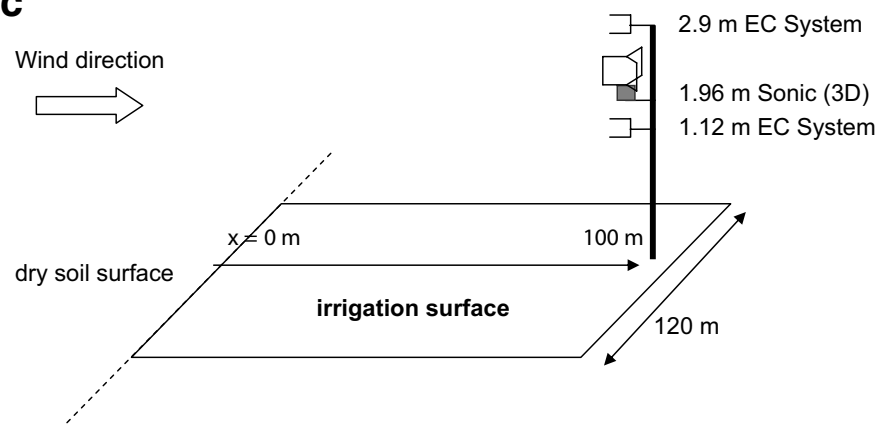

d

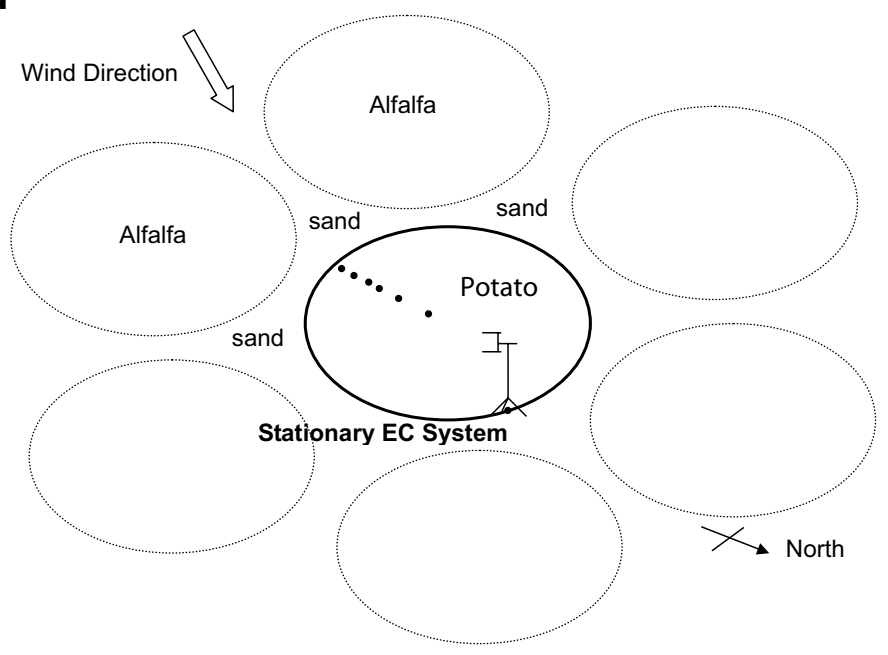


magnitude of the fluxes by the Lagrangian model, the source strength needs to be known. The water vapor fluxes measured at $1.12 \mathrm{~m}$ were utilized as a reference to determine the source strength. The source strength can also be calculated indirectly from measurements of mean wind speed and scalar concentration in conjunction with a Lagrangian model, as suggested by Wilson et al. (1982). LE measurements at $2.9 \mathrm{~m}$ were used to test the Lagrangian model predictive skills. A Gill tri-axial sonic anemometer positioned at $1.96 \mathrm{~m}$ from the surface was used to measure the wind velocity statistics and sensible heat flux $(H)$. The experimental setup is shown in Fig. 1c.

The sampling frequency was $21 \mathrm{~Hz}$ and the sampling period was $26 \mathrm{~min}$, resulting in 32,768 data points from each measured flow variable. Data with temporal trend (or non-steady) in the 26-min periods were discarded. Two periods of data on days 233 and 234 were analyzed in this study. There were 5, 17, and 7 runs in unstable, near neutral, and stable conditions, respectively. To ensure the LE measurements were reliable, only data larger than $50 \mathrm{~W} \mathrm{~m}^{-2}$ were used. This selection resulted in 17 runs, where the stability conditions $(z / L)$ were within -0.007 to -0.14 , to test the model performance. The longitudinal velocity was rotated along the mean wind direction so that $V$, the mean lateral velocity, was zero for each run. The internal boundary layer was found to be between 1.12 and $1.96 \mathrm{~m}$ at the measurement location. A unique feature of this experiment is that the water vapor source area is well defined.

\section{Potato site}

The experiment was carried out above a potato field between 3 June (day 154) and 13 June (day 164) 1992. The potato crop was planted in $0.91 \mathrm{~m}$ wide rows on a 800 $\mathrm{m}$ diameter irrigated circle (64 ha). The upwind surface was a triangular patch of desert soil and alfalfa field (see Fig. 1d). The potato field was irrigated every 1-3 days to ensure maximum productivity and limited water stress. The surface roughness height was $5 \mathrm{~mm}$ for the upwind desert soil and $50 \mathrm{~mm}$ for the potato field.

One stationary and one mobile EC system was used to evaluate the horizontal variations of fluxes of momentum, sensible heat, water vapor, and $\mathrm{CO}_{2}$ along the downwind progression from the transition edge. Both EC systems consisted of a three-dimensional sonic anemometer (ATI, model SWS211/3k) and an open-path infrared absorption spectrometer (Auble and Meyers 1992). The stationary system was located on the northeast side of the irrigated circle. Soil heat flux and net radiation measurements were also available at this location. The mobile system was placed at various distances from the upwind edge. Both systems were set at $4 \mathrm{~m}$ above the ground. The sampling frequency and averaging period were $10 \mathrm{~Hz}$ and $30 \mathrm{~min}$, respectively, and all the flux data were normalized using measurements from the stationary system. For reaching a maximum fetch, data were selected only when the wind was from the predominant southwesterly direction (between 220 and 240). After rotating the $x$-axis to the mean wind direction, the distance from the transition for the stationary system was $800 \mathrm{~m}$. The fluxes measured by the mobile system were along a progression of distances $-1 \mathrm{~m}$, $38.4 \mathrm{~m}, 72 \mathrm{~m}, 91 \mathrm{~m}, 136 \mathrm{~m}$, and $295 \mathrm{~m}$ - downwind from the edge. The mobile EC system moved from the first position to the last position between 1000 hours to 1600 hours. Data were selected from periods in which the turbulence conditions were stationary and the net radiation exceeded $500 \mathrm{~W} \mathrm{~m}^{-2}$. This selection resulted in 36 data points, 6 points at each location. The mean condition at each location was then taken by averaging these six data points.

An energy balance closure test [measured energy balance components (sensible, latent, and soil heat fluxes) matched the net radiation flux satisfactorily] at the stationary system has showed that this system was positioned well within the internal boundary layer. Based on the mean upwind meteorological conditions $\left(0.35 \mathrm{~m} \mathrm{~s}^{-1}\right.$ for friction velocity, $350 \mathrm{~W} \mathrm{~m}^{-2}$ for sensible heat flux, and $100 \mathrm{~W} \mathrm{~m}^{-2}$ for latent heat flux), the second order closure model was used to compute the flow field, which was then utilized to drive the Lagrangian model for estimating the variability in water vapor fluxes along the progression of downwind distances. Other details of this experiment can be found in Baldocchi and Rao (1995).

\section{Results and discussion}

Model simulations under homogeneous conditions

\section{Simulation of sagebrush experiment}

Before using these models for analyzing field measurements in planar inhomogeneous flows, we compared the Lagrangian model results under homogeneous conditions with field measurements. Figure $2 \mathrm{a}$ shows a typical predicted cumulative flux (SF6) at $10 \mathrm{~m}$ above the ground as a function of downwind distance from the transition edge (fetch) by the Lagrangian model and measurements (circles) under unstable conditions $\left(L=-55 \mathrm{~m}, u_{*}=0.4 \mathrm{~m} / \mathrm{s}\right.$, $\left.z_{\mathrm{o}}=0.14 \mathrm{~m}, h=0.75 \mathrm{~m}\right)$ over the homogeneous sagebrush canopy (Leclerc et al. 1997). Figure $2 \mathrm{~b}$ is the same as Fig. 2a but for a stronger unstable conditions $(L=-32 \mathrm{~m}$ and $u_{*}=0.29 \mathrm{~m} / \mathrm{s}$ ). In Figs. $2 \mathrm{a}$ and $2 \mathrm{~b}$, the solid line represents the Lagrangian model prediction with the $\sigma_{\mathrm{u}}$ profile from Eq. 8 and the dashed line represents simulation 

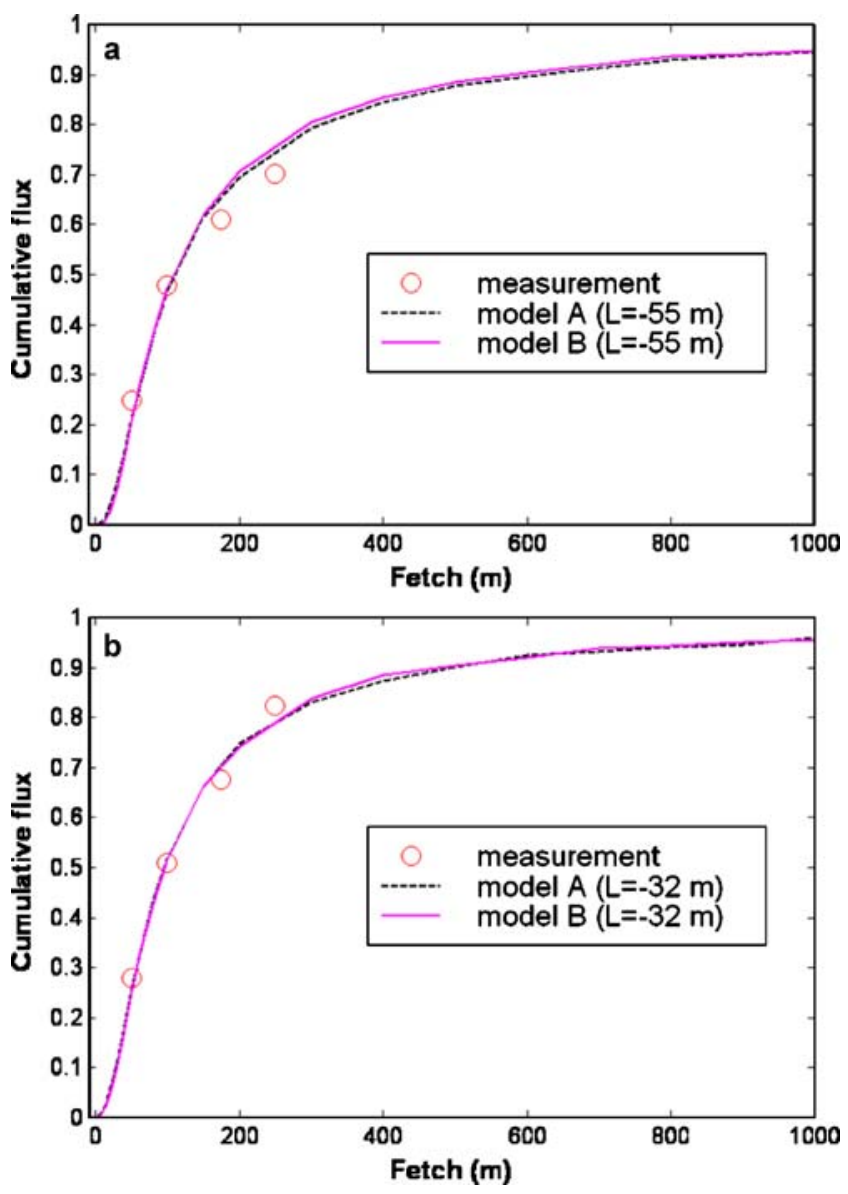

Fig. 2 a Comparison between measured and Lagrangian model predicted cumulative fluxes (SF6) at $10 \mathrm{~m}$ above the ground as a function of downwind distance (fetch) under unstable conditions ( $\left.L=-55 \mathrm{~m}, u_{*}=0.4 \mathrm{~m} / \mathrm{s}, z_{\mathrm{o}}=0.14 \mathrm{~m}, h=0.75 \mathrm{~m}\right)$ over the homogeneous sagebrush canopy. Model A (solid line) Lagrangian model prediction using the $\sigma_{\mathrm{u}}$ profile from Eq. 8, Model $B$ (dashed line) calculations with $\sigma_{\mathrm{u}}$ profile from Eq. 9. b As in a but for increased unstable conditions $\left(L=-32 \mathrm{~m}\right.$ and $\left.u_{*}=0.29 \mathrm{~m} / \mathrm{s}\right)$

with the $\sigma_{\mathrm{u}}$ profile from Eq. 9. Note that both $\sigma_{\mathrm{u}}$ profiles result in similar flux estimations. Hence, only the model predictions with Eq. 9 are presented hereafter. Good agreement between measured and predicted fluxes was found in the data presented in Fig. 2. The cumulative fluxes as a function of fetch for unstable $(L=-55)$, neutral, and stable $(L=100 \mathrm{~m})$ conditions are shown in Fig. 3. The observation height, surface roughness, and friction velocity in Fig. 3 are the same as in Fig. 2 though there were no flux measurements to compare under stable and neutral conditions. The $90 \%$ footprints for the unstable, neutral, and stable conditions in Fig. 3 are 500, 1,000, and 2,000 m, respectively. As expected, the $90 \%$ flux fetch requirement varies significantly with variations in atmospheric stability, and this fetch requirement becomes progressively longer for the same measurement height as the flow changes from unstable to neutral to stable conditions.

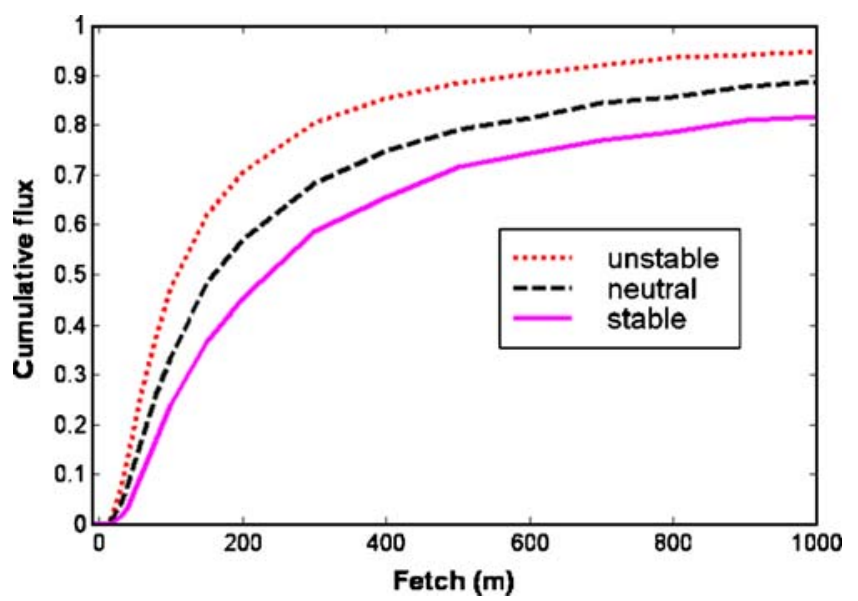

Fig. 3 Modeled cumulative fluxes as a function of fetch for unstable $(L=-55)$, neutral, and stable $(L=100 \mathrm{~m})$ conditions. Surface conditions as in Fig. 2a

\section{Simulation of peach orchard experiment}

Figure 4a shows a typical predicted normalized SF6 flux footprint $\left(z_{\mathrm{o}} f\right)$ as a function of horizontal distance from the measurement by the Lagrangian model (solid line) and measurements (circles) over the homogeneous peach orchard canopy (Leclerc et al. 2003) under near neutral conditions. Recall that footprint $(f)$ is defined by differentiating the normalized flux [i.e., $F(x, z) / S$ ] with respect to $x$ and has unit of $\mathrm{m}^{-1}$. In Fig. 4a, the measurement height, $z_{\mathrm{m}}$, is $6 \mathrm{~m}$ and the surface conditions are: $(z-d) / L=-0.0032$, $L \approx-1,000 \mathrm{~m}, u_{*} \approx 0.3 \mathrm{~m} / \mathrm{s}, \quad z_{\mathrm{o}} \approx 0.5 \mathrm{~m}, h \approx 4.0 \mathrm{~m}$, and $d \approx 2.5 \mathrm{~m}$. Figure $4 \mathrm{~b}$ is the same as Fig. $4 \mathrm{a}$ but for conditions: $(z-d) / L=-0.016, L \approx-200 \mathrm{~m}$ and $u * \approx 0.48 \mathrm{~m} / \mathrm{s}$. Figure $5 \mathrm{a}$ shows the same comparison as in Fig. $4 \mathrm{a}$ but for unstable conditions $(z-d) / L=-0.32, L \approx-11 \mathrm{~m}, u_{*} \approx 0.32 \mathrm{~m} / \mathrm{s}$, $z_{\mathrm{m}}=6 \mathrm{~m}, z_{\mathrm{o}} \approx 0.5 \mathrm{~m}, h \approx 4.0 \mathrm{~m}$, and $d \approx 2.5 \mathrm{~m}$. Figure $5 \mathrm{~b}$ is the same as Fig. $4 \mathrm{a}$ but for unstable condition $(z-d) / L=-0.15$, $L \approx-26 \mathrm{~m}, u * \approx 0.4 \mathrm{~m} / \mathrm{s}, z_{\mathrm{m}}=6 \mathrm{~m}, z_{\mathrm{o}} \approx 0.4 \mathrm{~m}, h \approx 3.1 \mathrm{~m}$, and $d \approx 2.1 \mathrm{~m}$. Good agreement between measurements and predictions was found in the data presented in Figs. 4 and 5. It should be noted that the measurement of the tracer footprint peak location and magnitude in Figs. 4 and 5 is tentative since flux gradients are largest close to the scalar source and peak location. As expected, under unstable atmospheric conditions, the peak source location (the source with the maximum contribution to the flux measurement) is closer to the measurement location than under neutral conditions. Also, the source area is more spread in nearneutral atmospheric stability conditions when compared to its unstable counterpart. The $90 \%$ footprints for Figs. $4 a-5 b$ are $100,80,25$, and 60 , respectively.

Leclerc et al. (2003) also compared their measurements with a Lagrangian stochastic dispersion model (Leclerc and Thurtell 1990). However, their model did not consider the 

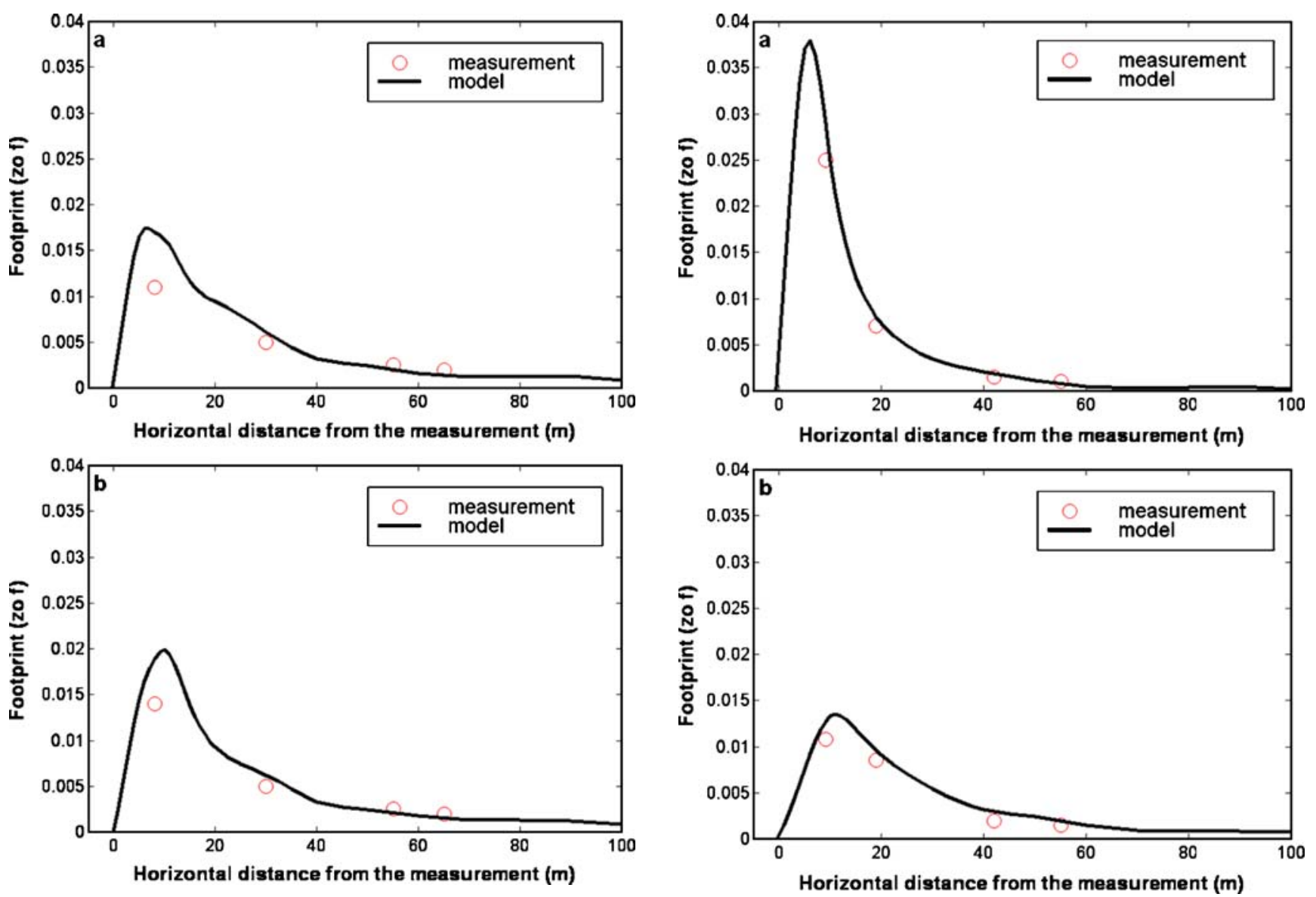

Fig. 4 a Comparison between measured and Lagrangian-modelpredicted normalized SF6 flux footprint $\left(z_{\mathrm{o}} f\right)$ as a function of horizontal distance from the measurement over the homogeneous peach orchard canopy under near neutral conditions. The measurement height, $z_{\mathrm{m}}$, is $6 \mathrm{~m}$ and the surface conditions are $(z-d) / L=-0.032$, $L \approx-1,000 \mathrm{~m}, u_{*} \approx 0.3 \mathrm{~m} / \mathrm{s}, z_{\mathrm{o}} \approx 0.5 \mathrm{~m}, h \approx 4.0 \mathrm{~m}$, and $d \approx 2.5 \mathrm{~m}$. b As in a but for surface conditions: $(z-d) / L=-0.016, L \approx-200 \mathrm{~m}$ and $u_{*} \approx 0.48 \mathrm{~m} / \mathrm{s}$

fluctuation of the streamwise wind velocity. Although it is commonly assumed that the fluctuation of the streamwise velocity is negligible, this assumption has not yet been tested with field data. The present model did consider the fluctuation of the streamwise velocity. To further examine the model performance, we also compared our model predictions, Leclerc et al.'s (2003) model predictions, and field measurements in a scatter plot (Fig. 6); both models are in good agreement with the measurements. In Fig. 6, the $R^{2}$ and standard error of estimation (SEE) values are 0.97 and 0.0022 , respectively, for the present study, and 0.90 and 0.0021 , respectively, for Leclerc et al. (2003). Figure 6 demonstrates that the Lagrangian model, which includes the fluctuation of the streamwise velocity, does not perform better than the one without this inclusion. This also indicates that the assumption: "the fluctuation of the streamwise velocity could be neglected" is valid.

Fig. 5 a Same as Fig. 4a but for unstable conditions $(z-d) / L=-0.32$, $L \approx-11 \mathrm{~m}, u_{*} \approx 0.32 \mathrm{~m} / \mathrm{s}, z_{\mathrm{m}}=6 \mathrm{~m}, z_{\mathrm{o}} \approx 0.5 \mathrm{~m}, h \approx 4.0 \mathrm{~m}$, and $d \approx 2.5 \mathrm{~m}$. b Same as Fig. 4 a but for unstable conditions $(z-d) / L=-0.15, L \approx-26 \mathrm{~m}$, $u_{*} \approx 0.4 \mathrm{~m} / \mathrm{s}, z_{\mathrm{m}}=6 \mathrm{~m}, z_{\mathrm{o}} \approx 0.4 \mathrm{~m}, h \approx 3.1 \mathrm{~m}$, and $d \approx 2.1 \mathrm{~m}$

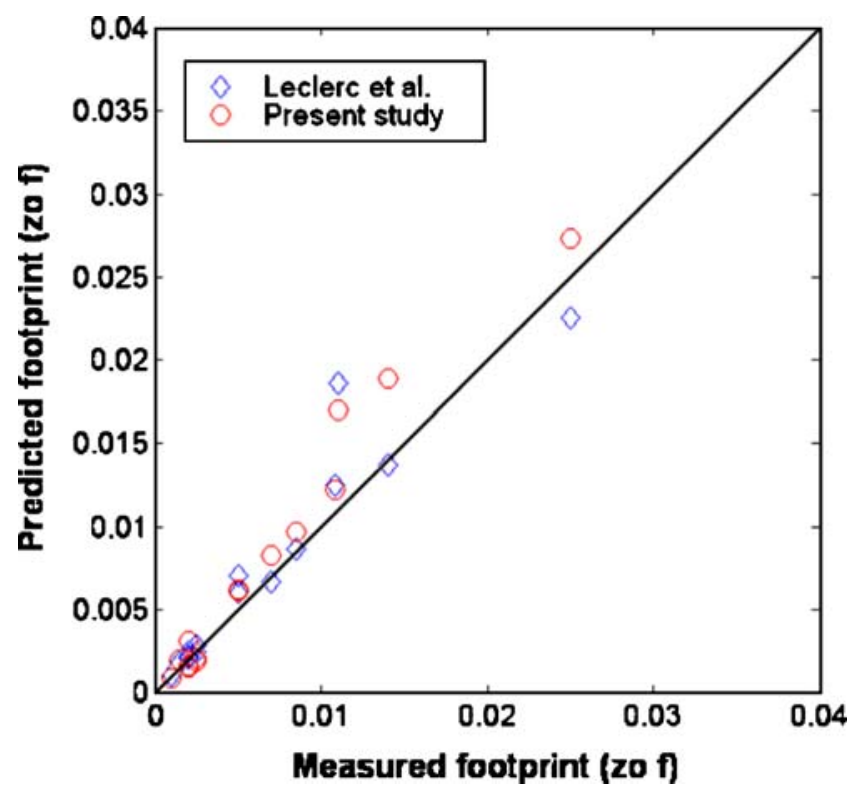

Fig. 6 Comparison between measured and model predicted footprint $\left(z_{\mathrm{o}} f\right)$. The $1: 1$ line is also shown 

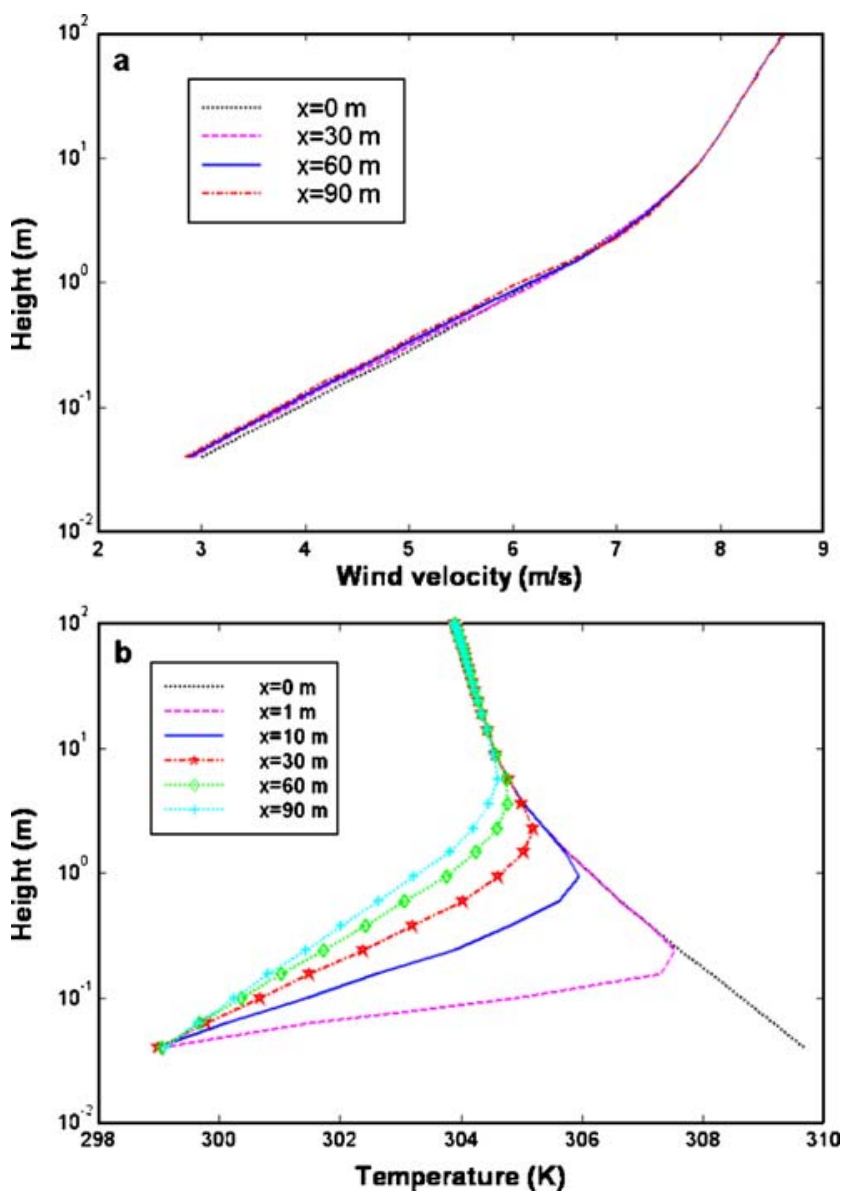

Fig. 7 a Evolution of the mean wind profiles along the inhomogeneous bare soil site, where the upwind condition $(x \leq 0$; dry soil surface) is unstable, and the downwind ( $x>0$; irrigation surface) condition is stable. The upwind boundary conditions are $\Theta_{\mathrm{o} 1}=313 \mathrm{~K}$, $u_{*_{\mathrm{o} 1}}=0.4 \mathrm{~m} \mathrm{~s}^{-1}$, and $H_{\mathrm{o} 1}=0.24 \mathrm{~m} \mathrm{~s}^{-1} \mathrm{~K}$. Here the subscript $\mathrm{o} 1$ denotes the upwind boundary conditions. b Same as Fig. 6a but for temperature

Model testing over the bare soil site

Before we discuss the Lagrangian model simulations, we first examined the velocity and temperature profiles solved by the second-order closure model over the bare soil area.

\section{Second-order closure model calculations}

Figure $7 \mathrm{a}$ shows the typical evolution of the mean wind velocity profiles from the upwind $(x \leq 0)$ to the downwind $(x>0)$ irrigated area where the atmospheric surface boundary conditions are: upwind surface, $\Theta_{\mathrm{o} 1}=313 \mathrm{~K}, u_{*} *_{\mathrm{o} 1}=0.4 \mathrm{~m} \mathrm{~s}^{-1}$, and $H_{\mathrm{o} 1}=0.24 \mathrm{~m} \mathrm{~s}^{-1} \mathrm{~K}$; and downwind surface at $x=30 \mathrm{~m}$, $\Theta_{\mathrm{o} 2} \approx 300 \mathrm{~K}, u_{* 02}=0.388 \mathrm{~m} \mathrm{~s}^{-1}$ and $H_{02}=-0.370 \mathrm{~m} \mathrm{~s}^{-1} \mathrm{~K}$; here the subscripts $\mathrm{o} 1$ and $\mathrm{o} 2$ denote the upwind and downwind boundary conditions at $z=\mathrm{z}_{\mathrm{o}}$, respectively. Note that the mean velocity profile does not change appreciably with downwind distance. Furthermore, this minor change is due to changes in local atmospheric stability conditions (from unstable to stable) and not due to roughness changes. Figure $7 \mathrm{~b}$ is the same as Figure $7 \mathrm{a}$ but shows the mean temperature profiles. Note the dramatic change in temperature profile due to the step change in surface temperature (from hot to cool) over the bare soil. Also, in Fig. 7b, the changes in temperature profiles become progressively smaller and smaller with distance, and the upper air layers (above $10 \mathrm{~m}$ from the ground) do not "sense" the wet surface despite the fact that the air has traveled some $90 \mathrm{~m}$ along the discontinuity. These simulations demonstrate that the upwind air was equilibrating with the downwind surface gradually, as expected for a surface with such a small $z_{\mathrm{o}}$. Similar temperature changes (in Fig. 7b) under local advection conditions were also found by the closure models in Rao et al. (1974), Naot and Mahrer (1991), and Wilson et al. (2001) and were also shown to be in good agreement with their field measurements.

\section{Model flux footprint predictions}

Using the flow and the second moments computed by the closure model, we consider the footprint of water vapor flux over the bare soil area. Figure 8a shows the computed footprint as a function of horizontal distance from the measurement for three observation heights (1.12, 1.96 and $2.9 \mathrm{~m}$, respectively), where the upwind atmospheric condition is unstable, and the downwind condition is stable. Here the fetch is $100 \mathrm{~m}$ (i.e., the tower is at $100 \mathrm{~m}$ from the boundary between irrigated and non-irrigated regions along the mean wind direction) and the atmospheric stability conditions were the same as Fig. 7a. In Fig. 8a, note that the source has a maximum contribution to the flux measurement at $1.12 \mathrm{~m}$, which is around $18 \mathrm{~m}$ away from the tower, and the source area expands further and further as the observation level increases.

Figure $8 \mathrm{~b}$ is the same as Fig. $8 \mathrm{a}$ but for near neutral upwind atmospheric conditions $\left(H_{\mathrm{o} 1}=0.02 \mathrm{~m} \mathrm{~s}^{-1} \mathrm{~K}\right)$. In Fig. 8b, the upwind surface is dry and under near neutral conditions. The downwind surface is irrigated and humid. So, when this dry upwind air flows over the downwind wet surface, water is evaporated and cools down the surface temperature and a stable downwind internal boundary layer is then formed. Figure $8 \mathrm{c}$ is the same as Fig. $8 \mathrm{a}$ but both the upwind and downwind atmospheric conditions are unstable (at upwind surface, $\Theta_{\mathrm{o} 1}=300 \mathrm{~K}, u_{*_{\mathrm{o} 1}}=0.4 \mathrm{~m} \mathrm{~s}^{-1}$, and $H_{\mathrm{o} 1}=$ $0.24 \mathrm{~m} \mathrm{~s}^{-1} \mathrm{~K}$; and at downwind distance $x=30 \mathrm{~m}, \Theta_{\mathrm{o} 2} \approx$ $293 \mathrm{~K}, u_{* 02}=0.398 \mathrm{~m} \mathrm{~s}^{-1}$ and $\left.H_{02}=0.13 \mathrm{~m} \mathrm{~s}^{-1} \mathrm{~K}\right)$. The results show that under unstable downwind conditions the footprint peak location is closer to the measurement point than the stable condition. Comparing Figs. $8 \mathrm{a}, 8 \mathrm{~b}$, and $8 \mathrm{c}$ reveals that the footprint (source area) under this in- 

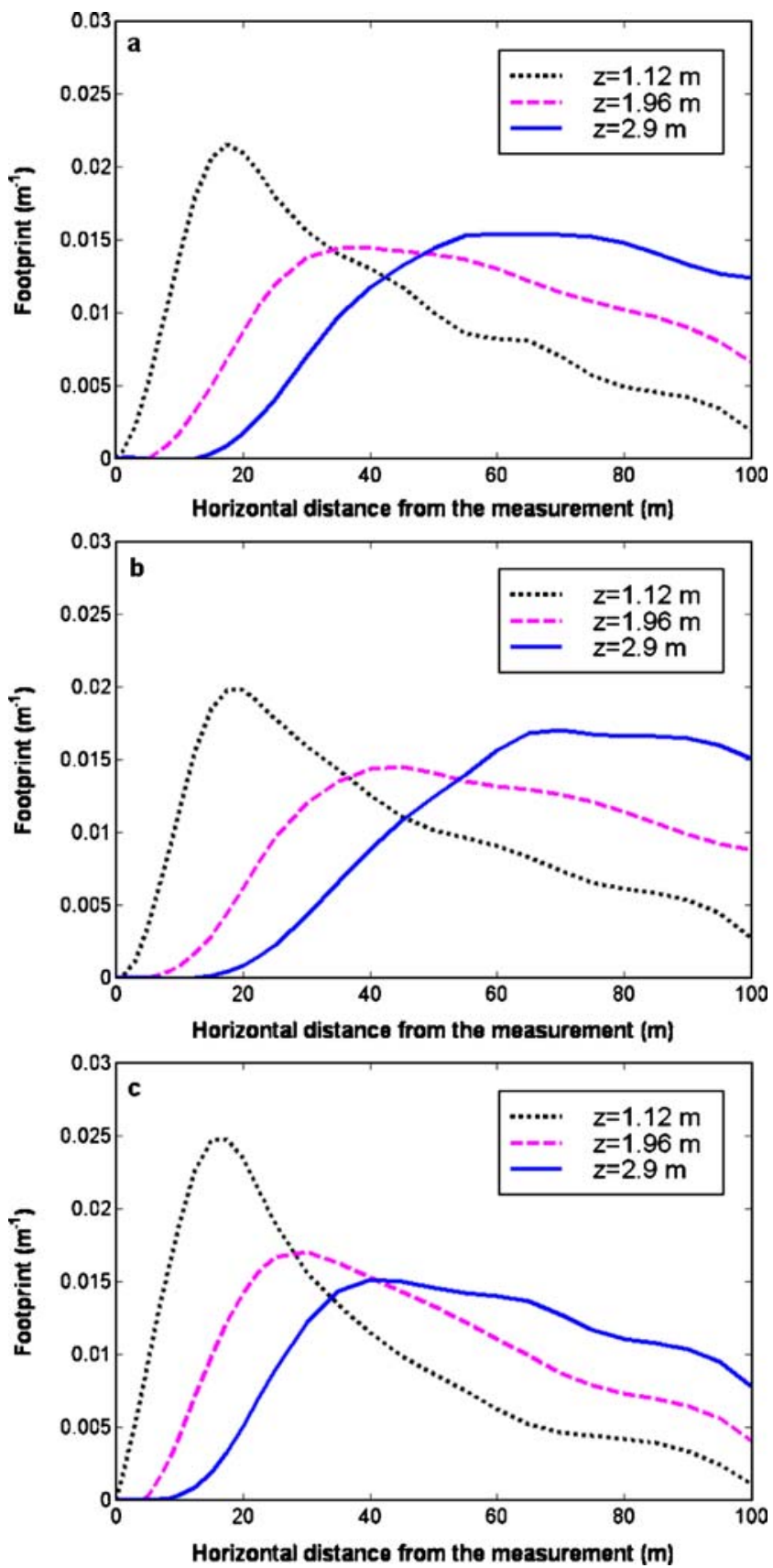

Fig. 8 a Variation of the footprint as a function of measurement height and horizontal distance from the measurement, where the upwind condition is unstable and the downwind condition is stable. Here the upwind boundary conditions are the same as in Fig. 7a. b As in a but the upwind atmospheric condition is near-neutral $\left(H_{\mathrm{O} 1}=\right.$ $0.02 \mathrm{~m} \mathrm{~s}^{-1} \mathrm{~K}$ ) and the downwind condition is stable. $\mathbf{c}$ As in a but the upwind and downwind atmospheric conditions are both unstable. The upwind boundary conditions are $\Theta_{\mathrm{o} 1}=303 \mathrm{~K}, u_{*_{0} 1}=0.4 \mathrm{~m} \mathrm{~s}^{-1}$, and $H_{\mathrm{o} 1}=0.24 \mathrm{~m} \mathrm{~s}^{-1} \mathrm{~K}$ homogeneity is only slightly influenced by the upwind atmospheric stability conditions and appears a little bit narrower if the atmospheric stability conditions become unstable. Another thing to remember is that the area under the footprint curves must integrate to unity.

The bare soil site experiment provides a baseline data set to test the Lagrangian model over a non-homogeneous surface since the source area for water vapor is (1) uniform, (2) spatially well defined, and (3) the momentum roughness change is negligible. Previous work by Hsieh et al. (1997, Figs. 8 and 9) demonstrated the need to include nonhomogeneity effects to improve scalar flux estimation by a Lagrangian model. Here, we explicitly consider inhomogeneity by using the mean velocity and atmospheric stability fields computed from the second-order closure model (vis-àvis MOST as in Hsieh et al. 1997). With the source strength determined from the water vapor flux measured at $1.12 \mathrm{~m}$, the Lagrangian dispersion model was applied to predict the water vapor flux at $2.9 \mathrm{~m}$. Figure 9 compares the water vapor flux measured by the EC system at $2.9 \mathrm{~m}$ and the model predictions. Good agreement between measurements and predictions was noted $\left(R^{2}=0.86 ; \mathrm{SEE}=24.94 \mathrm{~W} \mathrm{~m}^{-2}\right)$. This agreement demonstrates the usefulness of a coupled Lagrangian-Eulerian model for simultaneously estimating the scalar flux and footprint over an irrigated bare soil site experiencing a step change in surface temperature and water vapor.

Model testing over the potato site

The variations in mean wind velocity and temperature are presented in Baldocchi and Rao (1995) and will not be repeated here given that our focus is on longitudinal variations in latent heat flux. For this heterogeneous

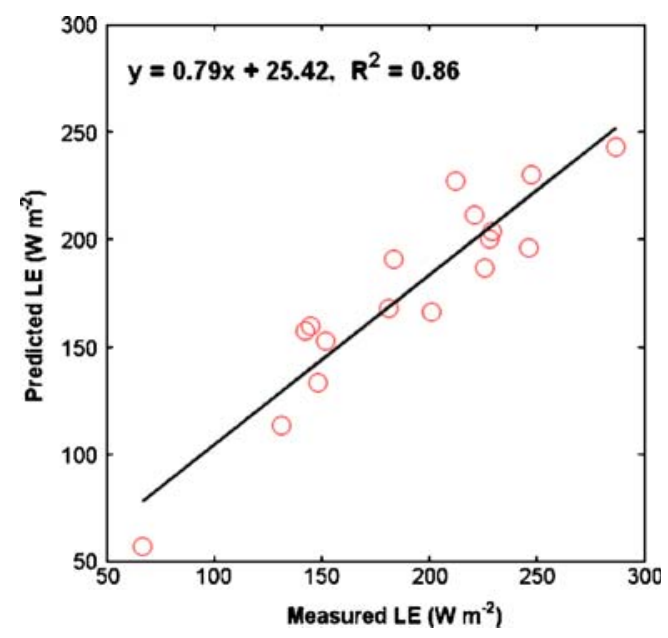

Fig. 9 Comparison between the EC-measured and Lagrangian-modelpredicted water vapor fluxes over the bare soil site at $z=2.9 \mathrm{~m}$. The regression line is also shown 


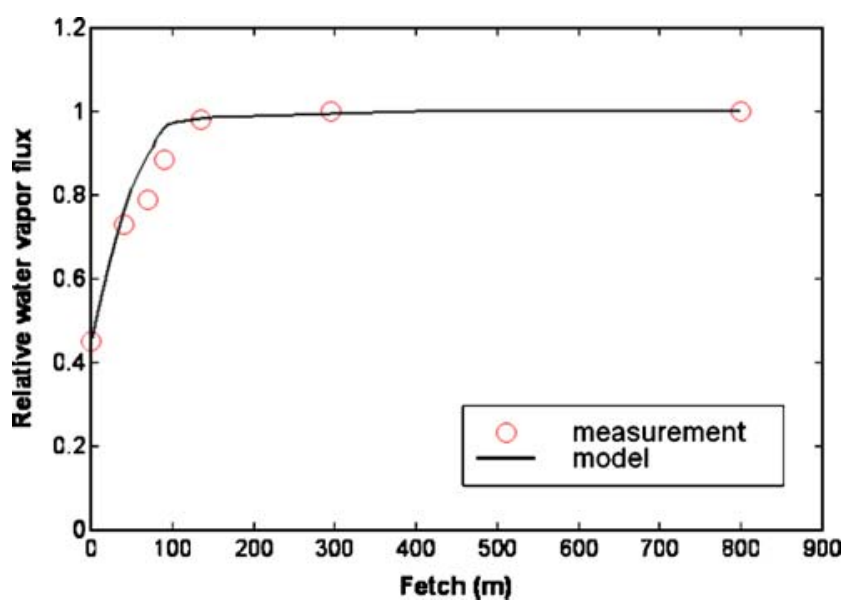

Fig. 10 Comparison between EC-measured and Lagrangian-modelpredicted water vapor fluxes as a function of downwind distance (fetch) over the potato site

surface, the upwind and downwind source strengths were determined using the water vapor fluxes measured at $x=$ $1 \mathrm{~m}$ downwind from the edge and at the stationary system $(x=800 \mathrm{~m})$, respectively. Given these source strengths, the Lagrangian model was used, in conjunction with the second-order closure model, to predict the water vapor fluxes along the downwind distances. Figure 10 compares the EC-measured and Lagrangian-model-predicted water vapor fluxes (measured at $4 \mathrm{~m}$ above the ground) as a function of downwind distance (fetch). Two features can be noted in Fig. 10: (1) the measured water vapor fluxes agrees well with model predictions in magnitude and variation trend; (2) both measurement and model prediction show that the $90 \%$ flux layer was reached around $100 \mathrm{~m}$ downwind from the transition edge. Also, both the measurements and model predictions reveal that, around $300 \mathrm{~m}$ downwind from the edge, the air became in good equilibrium with the irrigated potato surface, where the water vapor flux was the same as the water vapor flux $800 \mathrm{~m}$ downwind.

\section{Conclusions}

We investigated a two-dimensional Lagrangian stochastic dispersion model for predicting scalar fluxes and their footprint for planar homogeneous and inhomogeneous turbulent flows. For homogeneous surfaces, it was found that a Lagrangian model that includes fluctuation of streamwise velocity does not perform better than one without this inclusion. This also indicates that the assumption: "the fluctuation of the streamwise velocity could be neglected" is valid.
Above an inhomogeneous surface, the Lagrangian model was driven by the flow field generated from an Eulerian second-order model. Using this Eulerian-Lagrangian combination, we showed that Lagrangian model predictions of water vapor fluxes are in good agreement with field measurements over an irrigated bare soil site and an irrigated potato field. Future work will focus on extending this coupled Eulerian-Lagrangian approach to flows on complex terrain where $W(x, z)$ becomes significant and a recirculation zone in the mean streamlines may exist (e.g., Poggi and Katul 2007).

Acknowledgments The authors would like to thank the four anonymous reviewers for their helpful comments. We are grateful to Dennis Baldocchi for providing the irrigated potato data set and Marc Parlange for his support and help at the Campbell Tract Facility. C.-I.H. thanks the National Science Council, Taiwan for their support, and G.K. acknowledges support provided by the United States Department of Energy (DOE) through the Office of Biological and Environmental Research (BER) Terrestrial Carbon Processes (TCP) program (Grants \# 10509-0152, DE-FG02-00ER53015, and DE-FG02-95ER62083), and by the National Science Foundation (NSF-EAR 0628342).

\section{Appendix A: stability correction functions and Lagrangian time scale profiles}

1. For unstable conditions $(z / L<0)$ :

$$
\begin{aligned}
\psi_{m}= & -2 \ln \left(\frac{1+\phi}{2}\right)-\ln \left(\frac{1+\phi^{2}}{2}\right)+2 \\
& \times \tan ^{-1}(\phi)-\frac{\pi}{2}
\end{aligned}
$$

$t_{L}=\frac{k(z-d) u_{*}}{\sigma_{w}^{2} \phi_{h}}$

$\phi=(1-16(z-d) / L)^{1 / 4}$

$\phi_{h}=0.37(0.03-3(z-d) / L)^{-1 / 3}$

2. For neutral and stable conditions $(z / L \geq 0)$ :

$$
\begin{gathered}
\psi_{m}=1+5(z-d) / L \\
t_{L}=\frac{k(z-d) u_{*}}{\sigma_{w}^{2} \phi_{h}} \\
\phi_{h}=1+5(z-d) / L
\end{gathered}
$$




\section{Appendix B: boundary conditions for the second-order closure model}

The boundary conditions are based on Monin-Obukhov similarity theory (MOST) under neutral atmospheric stratification. Near the ground, the downwind boundary values (i.e., at $z \approx z_{\mathrm{o} 2} ; z_{\mathrm{0} 2}$ is the downstream surface roughness) for velocities are: $U\left(z_{\mathrm{o} 2}\right)=0$ and $W\left(z_{\mathrm{o} 2}\right)=0$. The boundary values for temperature are solved by assuming that the available energy is conserved through the downwind surface. In other words, the following equation is valid.

$\mathrm{H}_{\mathrm{0} 2}+\mathrm{LE}_{\mathrm{0} 2}=\mathrm{Rn}_{\mathrm{0} 2}-\mathrm{G}_{\mathrm{0} 2}=$ constant

where the subscript 02 denotes the downwind boundary parameter, $\mathrm{Rn}$ is the net radiation and $G$ is the soil heat flux. With the equilibrium flux-profile relations, Eq. A.8 can be expressed as

$-\left.\rho \mathrm{C}_{p} k z u_{* o 2} \frac{\partial \Theta}{\partial z}\right|_{z o 2}=R n_{o 2}-G_{o 2}-L E_{o 2}$,

where $\rho$ is the air density, $C_{\mathrm{p}}$ is the specific heat of air at constant pressure, and $u_{*_{\mathrm{o}} 2}$ is specified as

$u_{* o 2}=\left.k z \frac{\partial U}{\partial z}\right|_{z o 2}$

Equations A.9 and A.10 are solved together to determine the downwind boundary values for temperature.

With $u_{*}$ calculated by Eq. A.10 and $\theta_{*}$ calculated by

$\theta_{* 02}=\left.0.74 \mathrm{kz} \frac{\partial \Theta}{\partial z}\right|_{z o 2}$,

the boundary conditions for the second moments of velocity and temperature and the dissipate rate of turbulence kinetic energy are specified as follows:

$\overline{u^{\prime} u^{\prime}}=a_{u u} u_{*}^{2} ; \overline{v^{\prime} v^{\prime}}=a_{v v} u_{*}^{2} ; \overline{w^{\prime} w^{\prime}}=a_{w w} u_{*}^{2} ;$

$\overline{u^{\prime} w^{\prime}}=-u_{*}^{2}$

$\overline{\theta u^{\prime}}=a_{\theta u} \theta_{*} u_{*} ; \overline{\theta w^{\prime}}=-\theta_{*} u_{*}$

$\bar{\varepsilon}=k_{\varepsilon}\left(\overline{u^{\prime} u^{\prime}}+\overline{v^{\prime} v^{\prime}}+\overline{w^{\prime} w^{\prime}}\right)^{3 / 2} / k z_{o 2}$

In Eqs. A.12 and A.13, $a_{u u v v w w}$ and $a_{\theta u}$, are similarity constants.

As to the upstream boundary conditions, $\Theta_{\mathrm{o} 1}, u_{*_{\mathrm{o}} 1}$, and $\theta *_{0} 1$ are known/given (the subscript o1 denotes the upstream boundary parameter), and the second moments of velocity and temperature and the dissipate rate of turbulence kinetic energy are calculated by Eqs. A.12A.14; $U\left(z_{\mathrm{o} 1}\right)$ and $W\left(z_{\mathrm{o} 1}\right)$ are set to zero $\left(z_{\mathrm{o} 1}\right.$ is the upstream surface roughness.

\section{References}

Auble DL, Meyers TR (1992) An open path, fast response infrared absorption gas analyzer for $\mathrm{H}_{2} \mathrm{O}$ and $\mathrm{CO}_{2}$. Boundary-Layer Meteorol 59:243-256. doi:10.1007/BF00119815

Baldocchi D, Rao S (1995) Intra-field variability of scalar flux densities across a transition between a desert and an irrigated potato site. Boundary-Layer Meteorol 76:109-136. doi:10.1007/ BF00710893

Baldocchi DD, Falge E, Gu L, Olson R, Hollinger D, Running S, Anthoni P, Bernhofer C, Davis K, Fuentes J, Goldstein A, Katul G, Law B, Lee X, Malhi Y, Meyers T, Munger JW, Oechel W, Pilegaard K, Schmid HP, Valentini R, Verma S, Vesala T, Wilson K, Wofsy S (2001) FLUXNET: a new tool to study the temporal and spatial variability of ecosystem-scale carbon dioxide, water vapor and energy flux densities. Bull Am Meteorol Soc 82:2415-2435. doi:10.1175/1520-0477(2001)082<2415:FANTTS $>2.3 . C O ; 2$

Borgas MS, Flesch TK, Sawford BL (1997) Turbulent dispersion with broken reflexional symmetry. J Fluid Mech 332:141-156

Bouvet T, Wilson JD, Tuzet A (2007) Observations and modeling of heavy particle deposition in a windbreak flow. Boundary-Layer Meteorol 123:481-509. doi:10.1007/s10546-007-9156-y

Bouvet T, Loubet B, Wilson JD, Tuzet A (2006) Filtering of windborne particles by a natural windbreak. J Appl Meteorol Climatol 45:1332-1349. doi:10.1175/JAM2382.1

Brunet Y, Itier B, McAneney J, Lagouarde JP (1994) Downwind evolution of scalar fluxes and surface resistance under conditions of local advection. Part II: measurements over barley. Agric For Meteorol 71:227-245. doi:10.1016/0168-1923(94)90013-2

Brutsaert W (1984) Evaporation into the atmosphere: theory, history, and applications. Reidel, Dordecht

Campbell GS, Norman JM (1998) An introduction to environmental biophysics, 2nd edn. Springer, New York

Finn D, Lamb B, Leclerc M, Horst TW (1996) Experimental evaluation of analytical and Lagrangian surface-layer flux footprint models. Boundary-Layer Meteorol 80:283-308

Flesch TK (1996) The footprint for flux measurements, from backward Lagrangian stochastic models. Boundary-Layer Meteorol 78:399-404. doi:10.1007/BF00120943

Flesch TK, Wilson JD, Yee E (1995) Backward-time Lagrangian stochastic dispersion models and their application to estimate gaseous emissions. J Appl Meteorol 34:1320-1332. doi:10.1175/ 1520-0450(1995)034<1320:BTLSDM > 2.0.CO;2

Gash JHC (1986) A note on estimating the effect of a limited fetch on micrometeorological evaporation measurements. Boundary-Layer Meteorol 35:409-413. doi:10.1007/BF00118567

Horst TW, Weil JC (1992) Footprint estimation for scalar flux measurements in the atmospheric surface layer. Boundary-Layer Meteorol 59:279-296 . doi:10.1007/BF00119817

Horst TW, Weil JC (1994) How far is far enough?: The fetch requirements for micrometeorological measurement of surface fluxes. J Atmos Ocean Technol 11:1018-1025. doi:10.1175/ 1520-0426(1994)011<1018:HFIFET>2.0.CO;2

Hsieh CI, Katul GG (1997) The dissipation methods, Taylor's hypothesis, and stability correction functions in the atmospheric surface layer. J Geophys Res 102:16391-16405. doi:10.1029/ 97JD00200

Hsieh CI, Katul GG, Schieldge J, Sigmon JT, Knoerr KK (1997) The Lagrangian stochastic model for fetch and latent heat flux estimation above uniform and non-uniform terrain. Water Resour Res 33:427-438. doi:10.1029/96WR03136

Hsieh CI, Katul GG, Chi TW (2000) An approximate analytical model for footprint estimation of scalar fluxes in thermally stratified atmospheric flows. Adv Water Resour 23:765-772. doi:10.1016/ S0309-1708(99)00042-1 
Kader BA, Yaglom AM (1990) Mean fields and fluctuation moments in unstable stratified turbulent boundary layers. J Fluid Mech 212:637-662. doi:10.1017/S0022112090002129

Kaharabata SK, Schuepp PH, Ogunjemiyo S, Shen S, Leclerc MY, Desjardins RL, MacPherson JI (1997) Footprint considerations in BOREAS. J Geophys Res 102:29113-29124. doi:10.1029/ 97JD02559

Katul GG, Parlange MB (1992) An atmospheric stability Penman Brutsaert potential evaporation model. Water Resour Res 28:121-126. doi:10.1029/91WR02324

Kljun N, Kastner-Klein P, Fedorovich E, Rotach MW (2004) Evaluation of Lagrangian footprint model using data from wind tunnel convective boundary layer. Agric For Meteorol 127:189201. doi:10.1016/j.agrformet.2004.07.013

Kljun N, Rotach MW, Schmid HP (2002) A three-dimensional backward Lagrangian footprint model for a wide range of boundary-layer stratifications. Boundary-Layer Meteorol 103:205-226. doi:10.1023/A:1014556300021

Kurbanmuradov O, Sabelfeld K (2000) Lagrangian stochastic models for turbulent dispersion in the atmospheric boundary layer. Boundary-Layer Meteorol 97:191-218. doi:10.1023/A:100270 1813926

Leclerc MY, Thurtell GW (1990) Footprint prediction of scalar fluxes using a Markovian analysis. Boundary-Layer Meteorol 52:247258. doi:10.1007/BF00122089

Leclerc MY, Shen S, Lamb B (1997) Observations and large-eddy simulation modeling of footprints in the lower convective boundary layer. J Geophys Res 102:9323-9334. doi:10.1029/96JD03984

Leclerc MY, Meskhidze N, Finn D (2003) Comparison between measured tracer fluxes and footprint model predictions over a homogeneous canopy of intermediate roughness. Agric For Meteorol 117:145-158. doi:10.1016/S0168-1923(03)00043-1

Lee RL, Naslund E (1998) Lagrangian stochastic particle model simulations of turbulent dispersion around buildings. Atmos Environ 32:665-672. doi:10.1016/S1352-2310(97)00313-0

Luhar AK, Rao KS (1994) Source footprint analysis for scalar fluxes measured in the flows over an inhomogeneous surface. In: Gryning S-E, Millan MM (eds) Air pollution modeling and its application. Plenum, New York, pp 315-323

Marcolla B, Cescatti A (2005) Experimental analysis of flux footprint for varying stability conditions in an alpine meadow. Agric For Meteorol 135:291-301. doi:10.1016/j.agrformet.2005.12.007

McAneney KJ, Brunet Y, Itier B (1994) Downwind evolution of transpiration by two irrigated crops under conditions of local advection. J Hydrol (Amst) 161:375-388. doi:10.1016/00221694(94)90136-8

Naot O, Mahrer Y (1991) Two-dimensional microclimate distribution within and above a crop canopy in an arid environment: modeling and observational studies. Boundary-Layer Meteorol 56:223-244. doi:10.1007/BF00120421

Naslund E, Rodean HC, Nasstrom JS (1994) A comparison between two stochastic diffusion models in a complex three-dimensional flow. Boundary-Layer Meteorol 67:369-384. doi:10.1007/ BF00705439
Parlange MB, Katul GG, Cuenca RH, Levent Kavvas M, Nielsen DR, Mata M (1992) Physical basis for a time series model of soil water content. Water Resour Res 28:2437-2446. doi:10.1029/ 92WR01241

Peterson EW (1972) Relative importance of terms in the turbulent energy and momentum equations as applied to the problem of a surface roughness change. J Atmos Sci 29:1470-1476. doi:10.1175/1520-0469(1972)029<1470:RIOTIT>2.0.CO;2"

Poggi D, Katul GG (2007) The ejection-sweep cycle over gentle hills covered with bare and forested surfaces. Boundary-Layer Meteorol 122:493-515. doi:10.1007/s10546-006-9117-x

Rao KS, Wyngaard JC, Cote OR (1974) Local advection of momentum, heat, and moisture in micrometeorology. BoundaryLayer Meteorol 7:331-348. doi:10.1007/BF00240836

Reynolds AM (1998a) On the formation of Lagrangian stochastic models of scalar dispersion within plant canopies. BoundaryLayer Meteorol 86:333-344. doi:10.1023/A:1000673418479

Reynolds AM (1998b) On trajectory curvature as a selection criterion for valid Lagrangian stochastic dispersion models. BoundaryLayer Meteorol 88:77-78. doi:10.1023/A:1001183520153

Rodean H (1996) Stochastic Lagrangian models of turbulent diffusion. Meteorological Monographs, vol 26, no. 48, American Meteorological Society, p84

Schmid HP (2002) Footprint modeling for vegetation atmosphere exchange studies: a review and perspective. Agric For Meteorol 113:159-183. doi:10.1016/S0168-1923(02)00107-7

Sawford BL (1999) Rotation of trajectories in Lagrangian stochastic models of turbulent dispersion. Boundary-Layer Meteorol 93:411-424. doi:10.1023/A:1002114132715

Shir CC (1972) A numerical computation of air flow over a sudden change of surface roughness. J Atmos Sci 25:304-310. doi:10.1175/1520-0469(1972)029<0304:ANCOAF $>2.0 . C O ; 2$

Stull RB (1988) An introduction to boundary layer meteorology. Kluwer, Boston

Thomson DJ (1987) Criteria for the selection of stochastic models of particle trajectories in turbulent flows. J Fluid Mech 180:529 556. doi: $10.1017 / \mathrm{S} 0022112087001940$

Wichmann M, Schaller E (1986) On the determination of the closure parameters in higher-order closure models. Boundary-Layer Meteorol 37:323-341. doi:10.1007/BF00117481

Wilson JD, Flesch TK (1997) Trajectory curvature as a selection criterion for valid Lagrangian stochastic models. Boundary-Layer Meteorol 84:411-426. doi:10.1023/A:1000474206967

Wilson JD, Sawford BL (1996) Review of Lagrangian stochastic models for trajectories in the turbulent atmosphere. BoundaryLayer Meteorol 78:191-210. doi:10.1007/BF00122492

Wilson JD, Thurtell GW, Kidd GE, Beauchamp EG (1982) Estimation of the rate of gaseous mass transfer from a surface plot to the atmosphere. Atmos Environ 16:1861-1868. doi:10.1016/00046981(82)90374-2

Wilson JD, Flesch TK, Harper LA (2001) Micro-meteorological methods for estimating surface exchange with a disturbed windflow. Agric Meteorol 107:207-225. doi:10.1016/S01681923(00)00238-0 